\title{
Proposta de Identificação de Subcentros Urbanos com Base na Distribuição Espacial das Funções: caso da Cidade de Maputo - Moçambique
}

\author{
Proposal for Urban Subcenters identification based on the Spatial \\ Distribution Of Functions: Case of Maputo City - Mozambique
}

Tomé Francisco Chicombo ${ }^{1}$

\begin{abstract}
Palavras-chave:
Centralidades

Pontos de Interesse ArcGis
\end{abstract}

Keywords:

Centralities

Points of Interest

ArcGis

\begin{abstract}
Resumo
O presente trabalho de pesquisa apresenta uma proposta metodológica de identificação de novas centralidades funcionais urbanas com base nos dados dos pontos de interesse da plataforma Open Street Map. Por outro lado, dados coletados através do trabalho de campo, entrevistas também foram usados para o estudo, complementados com imagens do Google Earth. Os dados de pontos de interesse foram classificados de acordo com critérios pré-definidos representando funcionalidades urbanas. Cada um dos critérios foi atribuído um peso. Os pesos dos critérios foram calculados com base no método do Processo Analítico Hierárquico. Para tal, foram realizadas entrevistas junto a especialistas e indivíduos com maior experiência de vivência na área de estudo, tendo como base as suas percepções em relação a distribuição das funcionalidades urbanas. Os resultados das entrevistas foram introduzidos em matrizes que permitiram o cálculo dos pesos de cada critério. Ademais, os dados dos pontos de interesse foram editados e processados com a ajuda do aplicativo ArcGis onde foi produzido um mapa que mostra a distribuição espacial dos pontos de interesse e os respetivos níveis de centralidade. Portanto, foi possível identificar com o presente estudo alguns pontos de concentração fora do centro histórico da cidade de Maputo, o que mostra evidências de surgimento de novas centralidades funcionais como resultado de implantação de novas infraestruturas urbanas na área não central, principalmente relacionadas ao comércio e prestação de serviços.
\end{abstract}

\begin{abstract}
This study presents a methodological proposal for identification of new urban functional centralities based on data from the points of interest of Open Street Map platform. On the other hand, data collected through fieldwork interviews were also used for the study and complemented with Google Earth imagery. Points of interest data were classified according to pre-defined criteria representing urban features. Each criterion was assigned a weight. The criteria weights were calculated based on the Analytical Hierarchical Process (AHP) method. For this purpose, interviews were carried out with specialists and individuals with greater experience of living in the study area, based on their perception regarding to the distribution of urban functionalities. The results of interviews were introduced in matrices that allowed the calculation of weights for each criterion. In addition, points of interest data were edited and processed through ArcGis application, in which a map was produced showing the spatial distribution of the points of interest and the respective levels of centrality. Therefore, it was possible to identify from this study some points of concentration outside the historic center of the Maputo city, which show evidence of emergence of new functional centralities as a result of implementation of new urban infrastructure in the non-central area, mainly related to commerce and services provision.
\end{abstract}




\section{INTRODUÇÃO}

Estudos sobre a distribuição das centralidades urbanas têm grande importância no planejamento urbano, principalmente na mobilidade urbana. Segundo Sopha et al. (2016) a localização da distribuição dos centros urbanos desempenha um papel importante na medida em que reduz custos de distribuição, impactos ambientais e congestionamento do tráfego nas cidades.

As cidades são entendidas por Castells (1983) como sistemas vivos, feitos, transformados e experienciados por pessoas. Olhando para o espaço interno da cidade, importa referir que estudos sobre a sua estrutura e funções são de extrema importância porque permitem um melhor planejamento e gerenciamento do espaço urbano.

O espaço urbano é caraterizado por um lugar central para onde convergem a maior parte das pessoas concentrando maior parte de bens e serviços em relação a restante área. $\mathrm{O}$ centro de acordo com Castells (1983) é o local onde se concentram as principais atividades comerciais, de serviços, de gerenciamento público e privado, terminais de transportes e caraterizado por uma intensa construção verticalizada.
Milani e Silva (2009) definem a centralidade como a circulação contínua de consumidores, trabalhadores, automóveis, mercadorias e informação para determinados lugares. É de salientar a importância de se perceber que a intensidade desse movimento ou fluxo depende da importância de um determinado local e a sua capacidade de atrair mais pessoas. Daí que faz sentido analisar a centralidade do ponto de vista das funções destes locais.

Para Yu et al. (2020) um dos passos mais importantes para analisar a estrutura espacial urbana é a identificação das suas centralidades. A identificação de centralidades tem sido abordada em vários estudos. Numa primeira fase tais estudos utilizavam principalmente dados populacionais e de emprego e ao longo do tempo estudos sobre centralidades foram incorporando vários outros elementos.

Atentar para o fato de que o processo de surgimento de novas centralidades no espaço urbano é consequência do crescimento da cidade, tanto em termos demográficos como espaciais. Ferreira (2018) refere que neste processo são impulsionadas novas dinâmicas como surgimento de grandes superfícies comerciais e de serviços nas áreas pericentrais.

Vários estudos sobre a identificação de novas centralidades têm sido realizados apresentando metodologias e dados diferentes (quadro 1).

Quadro 1. Estudos realizados sobre centralidade urbana.

\begin{tabular}{|l|l|}
\hline Autores & Titulo \\
\hline Borgatti (2005) & $\begin{array}{l}\text { Estudo de centralidade considerando as categorias de trajetórias que o trafego } \\
\text { pode seguir e o método de propagação. }\end{array}$ \\
\hline Hellrvik et al. (2019) & $\begin{array}{l}\text { Proposta de uma metodologia onde se integram as atividades, a atração e a } \\
\text { acessibilidade o que se chamou de centralidade preferencial. }\end{array}$ \\
\hline Porta et al. (2006) & $\begin{array}{l}\text { Metodologia para análise de redes geográficas baseada na avaliação da múltipla } \\
\text { centralidade com base em gráficos das ruas, funcionando uma estrutura métrica } \\
\text { e não topológica, investigando a pluralidade de índices de centralidade entre } \\
\text { pares. }\end{array}$ \\
\hline Santos et al. (2019) & $\begin{array}{l}\text { Uso da técnica Delphi, AHP com a aplicação do modelo gravitacional para } \\
\text { identificação de prováveis novos centros através de uma análise multicritério no } \\
\text { Rio Grande de Sul. }\end{array}$ \\
\hline Sevtsuk e Mekonnen (2012) & $\begin{array}{l}\text { Análise de rede urbana de código aberto para ArcGis, que faz o cálculo de cinco } \\
\text { medidas de centralidade, a saber, o alcance, indice de gravidade, } \\
\text { entrelaçamento, proximidade e retidão. }\end{array}$ \\
\hline Siqueira (2014) & $\begin{array}{l}\text { Identificação de subcentros com base no estabelecimento de valores de corte, } \\
\text { estimativas econométricas e análise exploratória de dados espaciais onde são } \\
\text { usados dois parâmetros, a saber, o total de trabalhadores e a densidade de } \\
\text { emprego. }\end{array}$ \\
\hline Yu (2020) & $\begin{array}{l}\text { Análise da centralidade do ponto de vista da distribuição da função urbana } \\
\text { tendo usado três camadas a saber: dados de pontos de interesse, distância, } \\
\text { funções e a distribuição espacial dos centros urbanos. }\end{array}$ \\
\hline Zong et al. (2015) & $\begin{array}{l}\text { Identificação das mudanças de estrutura espacial das cidades, para o } \\
\text { desenvolvimento e validação de estratégias de planejamento adequadas, onde } \\
\text { propõem um índice de centralidade simples que pode ser aplicado a larga escala } \\
\text { sobre atividades humanas, identificando centros, estabelecendo vínculos } \\
\text { funcionais no espaço e identificando mudanças estruturais no espaço urbano } \\
\text { com base nas informações sobre atividades humanas. }\end{array}$ \\
\hline
\end{tabular}

Fonte: Autor. 
Como pode se constatar, estudos sobre centralidades urbanas apresentam várias metodologias, cada uma com seus pontos fortes e fracos. Em termos gerais um dos grandes desafios neste tipo de estudos é a disponibilidade de dados, principalmente nos países em desenvolvimento, que ainda não possuem instituições que se dediquem na coleta e armazenamento estruturado deste tipo de dados.

O presente trabalho constitui uma proposta de identificação de prováveis novas centralidades na cidade de Maputo, em Moçambique, dentro dos constrangimentos de disponibilidade de dados. Para tal foi assumida uma metodologia que tem como base de informação os dados disponibilizados pela plataforma Open Street Maps. Trata-se de uma plataforma que conforme Boeing (2019), fornece um valioso banco de dados geoespaciais brutos de fontes coletivas para a construção de modelos de redes de ruas urbanas para análise científica. Note-se que esta plataforma também oferece dados sobre pontos de interesse e suas funcionalidades, rede de estradas e funcionalidades nas suas adjacências tanto como de edifícios e suas funcionalidades.

Sobre esta plataforma há que reconhecer que ainda persistem dúvidas acerca da sua validade. Entretanto, Jiang et al. (2015) esclarecem que embora existam problemas de validade e confiabilidade das informações dos pontos de interesse, rede de estradas e edifícios obtidas pela informação geográfica voluntária, estes dados são úteis nos estudos sobre uso de solo. De acordo com estes autores a cobertura e precisão destas informações depende fortemente das fontes públicas online.

Deste modo, foram consideradas informações sobre os pontos de interesse, na medida em eles refletem o uso real de cada local. Para Long e Liu (2015) os dados sobre os pontos de interesse possuem informações no nível de subparcelas, disponíveis em fornecedores online, com uma cobertura quase global, com altas resoluções espaciais e em maioria dos casos disponíveis gratuitamente.
Contudo, nos estudos de centralidades urbanas usando pontos de interesse é importante que elementos que desempenham diferentes funções urbanas sejam atribuídos pesos diferenciados, tendo em conta que eles atraem pessoas com intensidades destintas. Sevtsuk e Mekonnen (2012) chamam atenção que as representações não ponderadas nas redes urbanas limitam estritamente a análise, ignorando todas as informações sobre as atividades realizadas nos pontos de interesse.

Para a atribuição de pesos as diferentes funcionalidades dos pontos de interesse, foi aplicado o método multicritério e processo de análise hierárquica, que segundo Taherdoost (2017) é um dos sistemas mais inclusivos considerados para tomar decisões com vários critérios e assume um problema de forma hierárquica. Este método permitiu fazer a comparação dos fatores de decisão de forma pareada, o que culminou com a atribuição dos pesos de cada tipo de funcionalidade urbana.

\section{ÁREA DE ESTUDO}

A cidade de Maputo, antes denominada de Lourenço Marques, é a capital da República de Moçambique e maior cidade do país, situada em seu extremo sul, a $25^{\circ} 58^{\prime} \mathrm{S} 32^{\circ} 35^{\prime} \mathrm{E}$, na margem da baía de Maputo. Faz fronteira com distrito de Marracuene a norte, município da Matola a oeste e noroeste, distrito de Boane a oeste, oceano índico a leste e com o distrito de Matutuine a sul.

A cidade, ao longo do tempo, foi passando por um processo de expansão da mancha urbana tendo originado processos de conurbação urbana com o município da Matola a oeste e com o distrito de Marracuene a norte. Entretanto, para o presente estudo foi feito um recorte (figura 1) representando a área de estudo que representa a região principal e contínua da cidade. 
Figura 1 - Localização da cidade de Maputo

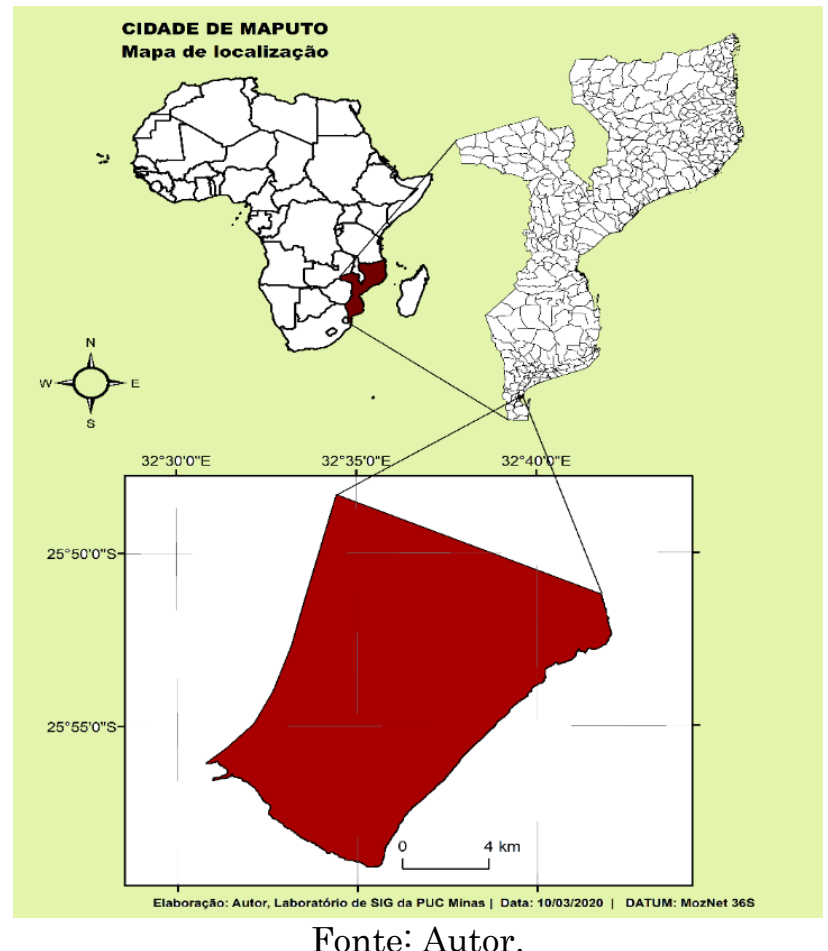

A cidade possui uma área total de $346 \mathrm{~km}^{2} \mathrm{e}$ situa-se numa zona temperada sul entre o trópico de capricórnio e círculo polar antártico. Devido a sua localização ela sofre efeitos das correntes marítimas, fazendo com que ocorram chuvas com boa regularidade, durante todos os meses do ano. Localiza-se uma posição litorânea e em fundo de um estuário na margem ocidental da baia de Maputo, uma posição privilegiada para as trocas comerciais, transporte pesca e lazer. O sítio urbano tem um relevo que varia de um plano costeiro para o leste, a baixa altitude, terminando em formas escarpadas que se desenvolvem no sentido norte-sul levando a uma planície mais alta, culminando em promontório.

Historicamente, a urbanização moçambicana surgiu dentro da matriz colonial, isto é, com acesso a recursos e portos para a exportação. Assim, existe uma longa história de assentamento urbano com vilas costeiras desenvolvidas por árabes, indianos e, posteriormente, comerciantes portugueses, que exportavam principalmente ouro, marfim e escravos.

Da mesma forma, a origem da cidade de Maputo, está associada a uma zona portuária que servia de um ponto de escoamento de recursos naturais e ligação com a hinterlândia. Este papel ainda é notório atualmente dentro da rede das cidades da região da África Austral, servindo de ponto de escoamento para cidades da África do Sul e Suazilândia. Esta zona passa por um processo de centralização da área central, caraterizado por construção de grandes centros comerciais, edifícios públicos e privados para prestação de serviços, comércio e habitação. É a área de maior concentração diurna de pessoas com uma ampla escala vertical.

O histórico de ocupação da cidade de Maputo pode ser analisado em dois momentos, a saber, a sua gênese em 1781 no período colonial com a criação de um presídio e o período após a independência do país. De acordo com Baia (2001) a cidade no âmbito da colonização portuguesa era constituída como centro administrativo com uma centralidade que sustentava a conquista e controle territorial em função das estratégias de dominação que visavam a garantia de acumulação de capital por parte da metrópole, no quadro de uma economia mercantil, mas com uma componente racial fundamentada na exclusão da população africana e servia de posto de produção e exportação de matéria-prima para os países colonizadores.

O padrão urbano é caraterizado por:

[...] um traçado geométrico regular adaptado à topografia, mas não racionalizado; o protagonismo urbanístico da rua, em que as vias principais mais largas se dispõem paralelamente à costa, desenhando uma estrutura de quarteirões lineares, com rua de ambos os lados, idênticos aos do período medieval; a 
existência de uma praça estruturante de cariz mais renascentista, articulando as vias e o acesso da língua de areia à margem continental, onde se localizam os equipamentos prioritários, apresentando uma constância e interação espacial; o espaço hierarquizado e a independência morfológica relativamente ao cerco muralhado (ROSSA, 2002; TEIXEIRA; VALLA, 1999 apud MELO 2017).

Ainda de acordo com Melo (2017) no período colonial, tempos em que a cidade era considerada a capital da Província Ultramarina de Moçambique, o desenvolvimento urbano surgiu através de situações criadas pela revolução industrial com um forte crescimento urbano gerado pelo grande afluxo de população maioritariamente rural, a introdução de novas funcionalidades e necessidades de saneamento e provisão de infraestruturas adequadas.

Neste período, a dinâmica de ocupação do solo seguia um padrão do urbanismo português em que as funções urbanas eram distribuídas obedecendo as cotas altimétricas. Em relação a esta dinâmica Melo (2017) faz a seguinte descrição:

Entre 1900 e 1940, a cidade cresce para norte e oeste de forma faseada, seguindo vários projetos de ampliação que refletem os mesmos princípios urbanísticos, a consolidação das estruturas públicas, áreas meramente residenciais, acentuando-se a separação entre diferentes usos do solo, que remete para outra característica do urbanismo português, nomeadamente uma ocupação diferenciada segundo cotas altimétricas: a cidade alta, mais fresca e arejada, destinada aos edifícios administrativos, às principais instituições cívicas e religiosas e às residências das classes mais altas; e a cidade baixa, destinada às atividades marítimas, aos serviços e ao comércio, bem como às classes mais baixas, junto ao porto e aos locais de emprego (MENDES, 1985; MORAIS, 2001; TEIXEIRA; VALLA, 1999 apud MELO, 2017).

No período pós-colonial a ocupação foi marcada por medidas estruturais como com a participação de investidores privados, nacionais e internacionais, uma pressão cada vez maior no centro urbano. Melo (2017) considera que essa situação exerceu uma crescente pressão imobiliária sobre as áreas semiurbanizadas mais próximas e também já nas mais afastadas com a construção de edifícios administrativos, de serviços residenciais para classes média e alta podendo envolver processos de gentrificação, a construção de habitações subsidiadas pelo estado, a formulação de projetos urbanísticos, a implementação de grandes superfícies comerciais, equipamentos e infraestruturas viárias.

Atualmente o centro histórico é caraterizado pelo surgimento de novos edifícios privados (sedes de instituições bancárias, centros comerciais) e públicos (edifícios ministeriais e de administração da justiça). Estas edificações geralmente foram erguidas em áreas que não tinham sido ocupadas no período colonial, de maior declividade ou com lençol freático elevado. Melo (2017) enfatiza que este processo rompeu com o princípio de urbanismo português de adaptação à topografia e respeito pelas condições naturais de cada local.

Assim, de acordo com Maloa e Nascimento Júnior (2018) a situação atual da urbanização na cidade de Maputo resulta do somatório do processo colonial urbano e pós-colonial que perfaz múltiplas partes enquadradas num mosaico urbano de geometria intricada que consiste em duas realidades ("zona cimento" e "zona caniço") que constituem duas realidades que tendem a desvanecer-se cursando-se, sobrepondo-se e justapondo-se a outras realidades que foram ganhando forma $e$ expressão no espaço urbano.

As denominações de "zona cimento" e "zona caniço" são os termos usados para se referir às duas áreas que representam a dicotomia que carateriza a urbanização na cidade de Maputo. De acordo com a explicação de Araújo (2003) a primeira que também é chamada de área urbana obedece uma planta ortogonal com rede viária pavimentada, serviços de saneamento básico, redes de abastecimento de água, energia elétrica e telecomunicações, construções verticalizadas, em geral, concentração de comércio, serviços e algumas indústrias. A segunda área chamada de suburbana é caraterizada por bairros não planejados e planta indiferenciada ou anárquica, elevada densidade da ocupação do solo, dificuldade de circulação, falta de área para serviços, construções horizontalizadas, serviços de saneamento inexistentes, deficiente rede de abastecimento de água, energia elétrica e de telecomunicações. 


\section{METODOLOGIA}

Em termos gerais o presente trabalho teve como base metodológica a leitura bibliográfica, o processamento de dados referentes dos pontos de interesse fornecidos pela plataforma Open Street Maps, a análise de imagens Google Earth e trabalho de campo.Para o estudo proposto foram usadas duas fontes de dados. Uma de dados secundários obtidos a partir uma base de dados raster obtida na plataforma Open Street Map (2020) e outra de dados primários através de um inquérito. O Open Street Map é uma plataforma gratuita e editável de todo o mundo que está sendo construído por voluntários que coletam informações dirigindo, andando de bicicleta ou andando pelas ruas e caminhos, e em torno das áreas que registram todos os seus movimentos usando recetores GPS (Sistema de Posicionamento Global). Essas informações são usadas para criar um conjunto de pontos e linhas que podem ser transformados em mapas ou usados para navegação. No caso do presente trabalho a camada de dados usada foi referente a pontos de interesse que possuem informação sobre a distribuição espacial das funções urbanas.
Os resultados das entrevistas serviram para atribuição de importâncias relativas dos critérios, o que permitiu calcular os pesos aos fatores usados para a identificação de prováveis novas centralidades funcionais na cidade.

Os dados referentes ao mapa dos pontos de interesse foram pré-analisados possibilitando a correção e edição de informações em falta. Através da informação coletada em trabalho de campo foi possível comparar com a constante nos pontos de interesse. Para os casos onde esta informação não constasse era feita a edição dos dados do raster. Foi necessário editar os dados das camadas de modo a introduzir a variável peso que foi usada para a elaboração dos mapas. Entretanto, os valores dos pesos de cada critério foram calculados com base método de Analytic Hierarchy Process (AHP), onde foram usados resultados das entrevistas.

A implementação das entrevistas seguiu uma amostragem intencional, na medida em que a escolha dos respondentes dependeu do julgamento do pesquisador.

Para o estudo foram considerados os seguintes critérios (Quadro 2) para a análise de centralidade funcionais na área em estudo.

Quadro 2. Descrição dos critérios.

\begin{tabular}{|l|l|}
\hline Local & Descrição \\
\hline $\begin{array}{l}\text { Administração } \\
\text { Pública }\end{array}$ & Repartições públicas e equipamentos urbanos de prestação de serviços \\
\hline Comercial & Mercado, centro comercial, loja, prestação de serviços. \\
\hline Educacional & Universidades, colégios, escolas de diferentes níveis, instituições de pesquisa \\
\hline Financeiro & Bancos, casas de câmbio e caixas eletrônicas (ATM) \\
\hline Industrial & Indústrias, montadoras \\
\hline Recreação & Estádio, piscina, museu, ginásio, igreja, jardim zoológico, cinema, praças, etc. \\
\hline Residencial & Locais de residência \\
\hline Restauração & Restaurantes, cafés, bares, etc. \\
\hline Saúde & Hospitais e clínicas \\
\hline Transportes & $\begin{array}{l}\text { Estação Ferroviária (estação de metrô), paragem de transportes públicos de } \\
\text { passageiros, aeroportos e portos. }\end{array}$ \\
\hline
\end{tabular}

Fonte: Autor 
Dada a necessidade da atribuição do nível de importância para cada critério foram usadas as escalas segundo o quadro 3.

Quadro 3. Descrição das escalas.

\begin{tabular}{|c|l|}
\hline Escala de importância & Descrição \\
\hline 1 & Os dois locais concentram pessoas na mesma medida \\
\hline 3 & Um dos locais concentra pessoas um pouco mais que o outro \\
\hline 5 & Um dos locais concentra moderadamente mais pessoas que o outro \\
\hline 7 & Um dos locais concentra intensamente pessoas que o outro \\
\hline 9 & Um dos locais concentra muito intensamente pessoas que o outro \\
\hline
\end{tabular}

Fonte: Adaptado de Taherdoost (2017)

Depois de aplicada do método AHP foram encontrados os pesos de cada critério. Os resultados estão apresentados na Tabela 1.

Tabela 1. Pesos dos critérios.

\begin{tabular}{ll}
\hline CRITÉRIO & PESO \\
\hline Comércio & 0.4253 \\
Serviços Públicos & 0.1948 \\
Serviços Bancários & 0.1097 \\
Educação & 0.0987 \\
Serviços de Saúde & 0.0714 \\
Restauração & 0.0444 \\
Recreação & 0.0282 \\
Residencial & 0.0275 \\
\hline
\end{tabular}

Fonte: Autor

Para o cálculo da consistência dos resultados dos pesos encontrados foi foram usados os valores do índice randômico de acordo com a Tabela 2. Segundo a escala de Saaty, a inconsistência máxima permitida para matriz quadrada de ordem 8 é de 1.41. Este valor é usado para o cálculo da consistência, que no caso foi menor que 0.1 , satisfazendo assim os requisitos da consistência.

Tabela 2. Índice Randômico Médio do AHP

\begin{tabular}{l|c|c|c|c|c|c|c|c|c|c}
\hline Ordem da matriz & 1 & 2 & 3 & 4 & 5 & 6 & 7 & 8 & 9 & 10 \\
\hline RI & 0 & 0 & 0.58 & 0.9 & 0.12 & 1.24 & 1.32 & 1.41 & 1.45 & 1.49 \\
\hline
\end{tabular}

Fonte: Saaty (1987).

O trabalho de campo (baseado na vivência do autor na área de estudo) foi importante modo a confirmar ou identificar e caraterizar algumas funcionalidades em pontos de interesse onde esta informação seja duvidosa ou inexistente. Serviu também como base para a abordagem teórica sobre os processos e formas espaciais na área de estudo.

Por conseguinte, o raster contendo informação dos pontos de interesse foi editado usando a ferramenta ArcGis de modo a acrescentar um campo que representa o peso de cada critério. Depois da edição do raster foi feito o seu processamento. $\mathrm{O}$ processamento consistiu na classificação dos pontos de interesse usando como base os pesos cujos valores foram calculados anteriormente (ver quadro 4).

\section{RESULTADOS E DISCUSSÃO}

Os resultados a serem discutidos no presente trabalho de pesquisa são referentes a processamento dos dados referentes aos pontos de interesse no aplicativo ArcGis, do trabalho de campo e na observação de imagens via Google Earth.

A figura 2 ilustra a distribuição espacial dos pontos de maior ou menor atração na área de estudo. Nota-se que o comércio segundo 
resultados do inquérito realizado é aquele que apresenta maior nível de atração de pessoas e consequentemente com maior peso. Por isso, no mapa, os lugares que apresentam maior intensidade de atração devem ser entendidos como locais onde existe maior concentração de atividades comerciais.

Figura 2 - Mapa dos pontos de interesse e seus níveis de centralidade na cidade de Maputo.

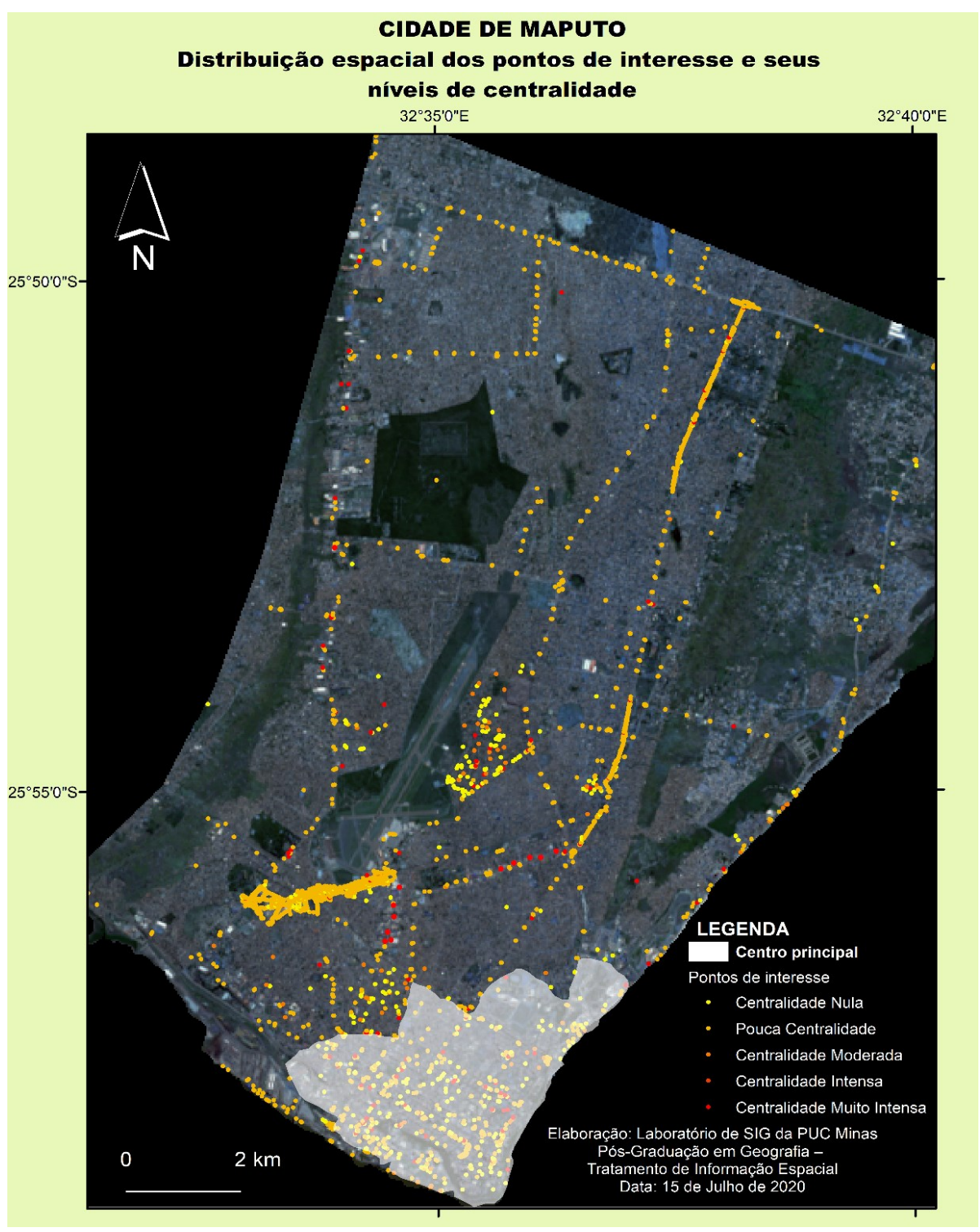

Fonte: Autor.

O mapa mostra pontos amarelados que representam menor concentração ou nula e pontos vermelhos que representam áreas de maior concentração segundo a legenda. É possível notar o surgimento de locais que vão concentrando mais pessoas fora do centro histórico. Entretanto, a área central continua sendo aquela que atrai mais pessoas devido a maior concentração de serviços e comércio.

Alguns desses pontos de interesse fora do centro histórico representam áreas compostas por estações de abastecimento de combustível, cercadas de lojas de conveniência, estabelecimentos de prestação de serviços e comerciais. É notório o movimento cada vez mais acentuado de pessoas nestas áreas que vão se beneficiando dos serviços e produtos que antes só estavam disponíveis no centro histórico da cidade. Este fenômeno contribui para o descongestionamento do centro da cidade e consequentemente o surgimento de novas centralidades funcionais na cidade facilitando a mobilidade urbana.

Outro elemento importante que o mapa ilustra é o fato de que grande parte pontos de maior concentração que vão surgindo na periferia estão localizados ao longo das principais vias de acesso. Novas infraestruturas 
cujas funções urbanas geram maior atração estão sendo erguidas ao longo destas avenidas. Fatores como a dificuldade de obtenção de espaço na zona central e a existência de terras não ocupadas na zona não central são responsáveis na descentralização de funcionalidades urbanas no município de Maputo. No entanto, o comércio e a prestação de serviços são as funções que estão registando maior descentralização. Por outro lado, registrou-se nos últimos anos a construção cada vez maior de edifícios públicos e privados no centro da cidade. Trata-se de uma opção que contribui para o maior congestionamento na área central da cidade e contribuindo negativamente para a mobilidade urbana.

Na zona pericentral do município de Maputo, existem algumas áreas que vão desempenhando o papel de maior atração de pessoas contribuindo também para o descongestionamento do centro histórico. Estas áreas são vistas como núcleos funcionais situados ao longo de algumas avenidas dentro da cidade (figura 3). As principais funcionalidades existentes nestas novas centralidades são o comércio (venda a retalho ou atacado) e prestação de serviços.

Figura 3 - Exemplos de núcleos funcionais.

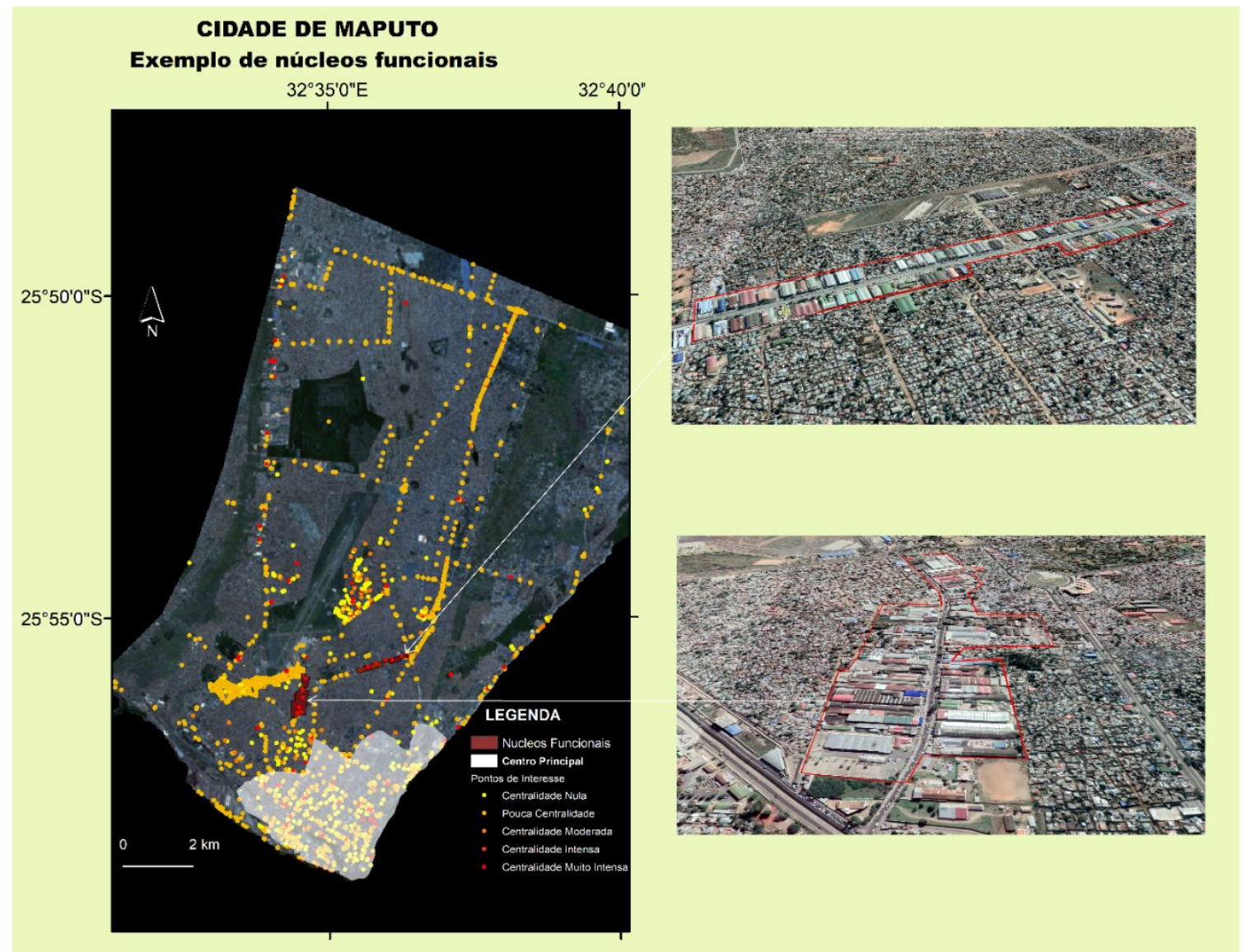

Fonte: Google Earth Pro.

Estes núcleos criam uma dinâmica de concentração dentro da cidade, reduzindo a pressão sobre o centro histórico na medida que vários serviços e produtos já podem ser encontrados neles. Corrêa (1995) chama esta dinâmica de coesão e as áreas especializadas. Para o autor este processo é definido como aquele movimento que leva as atividades a se localizarem juntas formando economias externas de aglomeração. Neste caso, segundo a abordagem do autor estamos perante uma dinâmica de funcionalidades de natureza distinta e complementares constituídas por centros comerciais, unidades de fabricação, companhias de seguros, bancos, sede de empresas industriais com ligações entre si, tanto à montante como à jusante, uma realidade que também contribui para o descongestionamento do centro da cidade e o surgimento de novas centralidades.

Outro cenário que se verifica na cidade e vai contribuindo para o surgimento de novas centralidades é a construção de novos centros comerciais fora do centro principal, que são representados pelos pontos de centralidade intensa ou muito intensa como ilustra figura 4 . 
Figura 4 - Exemplo de novas centralidades.

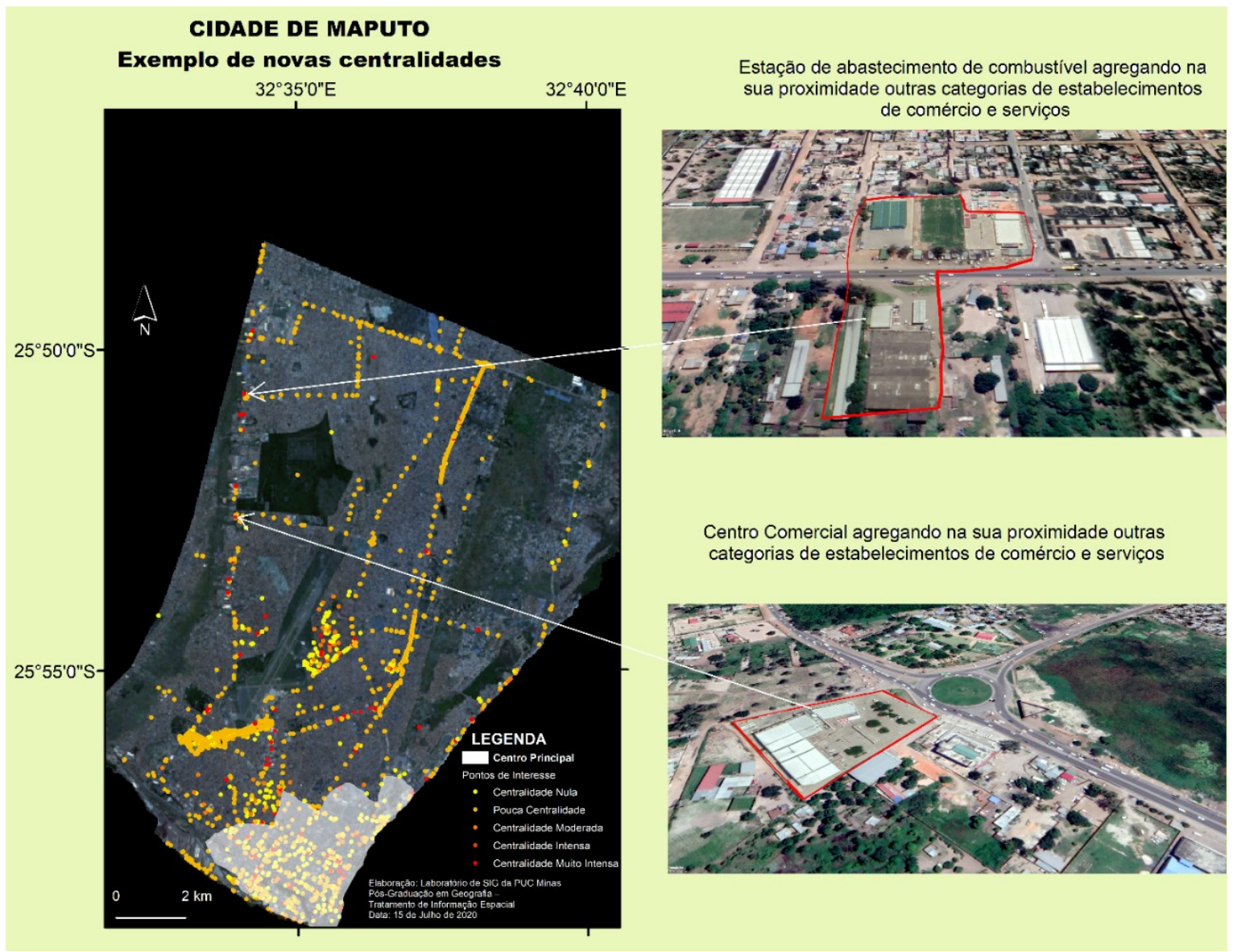

Fonte: Google Earth Pro.

Estes centros comerciais agregam na sua proximidade outras categorias de estabelecimentos comerciais e serviços com funções de natureza distinta, da mesma linha ou até complementares como bancos, farmácias, restaurantes, pastelarias entre outras funcionalidades.

O surgimento destes pontos de concentração nas periferias do centro resulta principalmente da falta de espaço no centro, sendo que geralmente ocupam espaços não ocupados. Trata-se de um processo que acompanha a implosão urbana resultante da reclassificação urbana por decreto, onde áreas rurais foram acrescentadas a área urbana, com o surgimento de novos bairros. Segundo Correa (1995) esta descentralização torna o espaço urbano mais complexo, com vários núcleos secundários de atividades, o que gera economia de transporte e para o consumidor.

\section{CONCLUSÕES}

Um dos maiores desafios nos estudos de centralidades urbanas é a disposição de dados que operacionalizem as metodologias propostas para este tipo de estudos, principalmente em países em desenvolvimento como é o caso de Moçambique. Esta situação faz com que estes tipos de estudos sejam escassos ou inexistentes, e quando existem são realizados com um conjunto limitado de dados.

No caso de se trabalhar com dados sobre funcionalidades urbanas, identificar suas centralidades constitui uma tarefa de extrema importância na medida em que contribui para tomada de decisões que permitem a resolução de certos problemas urbanos como é o caso dos custos elevados de distribuição dentro do espaço urbano e os congestionamentos no tráfego.

Políticas de planejamento e gerenciamento urbano devem ter em conta as acessibilidades, pois elas moldam a distribuição espacial das funções urbanas. Deste modo, promove-se um equilíbrio no desenvolvimento urbano. Assim, 
estudos sobre funções urbanas e centralidades são necessários para prover informações que ajudem na tomada de melhores decisões.

$\mathrm{O}$ presente trabalho de pesquisa fez uma análise, com base nos dados disponíveis, os possíveis novos centros funcionais que vão criando uma maior atração de pessoas. Os resultados do mapa mostram alguns pontos de maios concentração na área pericentral, que tendem a criar novas centralidade funcionais dentro do espaço urbano na cidade de Maputo.

Assim, o trabalho buscou contribuir para mais uma proposta metodológica em que procurou-se mostrar a possibilidade do uso dos dados da plataforma Open Street Maps nos estudos de centralidade funcionais urbanas, na medida em que estes dados são cada vez mais confiáveis e abrangentes.

\section{REFERÊNCIAS}

ARAÚJO, G.M. Os espaços urbanos em Moçambique. GEOUSP Espaço e Tempo, ${ }^{\circ} 14$, pp. 165- 182, 2003. https://doi.org/10.11606/issn.21790892.geousp.2003.123846

BAIA, A. H. M. Os meandros da urbanização em Moçambique. Espaço e Tempo, n ${ }^{0} 29$, pp. 03 30, 2011. http://dx.doi.org/10.11606/issn.21790892.geousp.2011.74202.

BOEING, G. Street Network Models and Measures for Every U.S. City, County, Urbanized Area, Census Tract, and ZillowDefined Neighborhood. Urban Sci, v. 3, n. 28, 2019.

https:// doi.org/10.3390/urbansci3010028.

BORGATTI, S. P. Centrality and network flow. Social Networks, v. 27, p. 55-71, 2005. https://doi.org/10.1016/j.socnet.2004.11.008.

CASTELLS, M. The city and the grassroots. Edward Arnold, 1983.

CORRÊA, R. L. O Espaço Urbano. Editora Ática, Série Princípios, 3a edição, no 174, p.1-16, 1995. FERREIRA, H. M. Análise Critica da Noção de Policentrismo: Uma Contribuição ao Estudo da Centralidade em Cidades Médias. GEOgraphia, v. 20, n. 44, 2018. https://doi.org/10.22409/GEOgraphia2018.v1i 44.a14406

GOOGLE EARTH PRO. Cidade de Maputo Moçambique. Coordenadas $25^{\circ} 58^{\prime} \mathrm{S} 32^{\circ} 35^{\prime} \mathrm{E}$. Acesso em: 26 Março. 2021.

HELLERVIK, A.; NILSSON, L.; ANDERSON, C. Preferential centrality - A new measure unifying urban activity, attraction and accessibility. Urban Analytics and City
Science, v. 46, n. 7, p. 1331 - 1346, 2019. https://doi.org/10.1177/2399808318812888.

JIANG, S. et al. Mining point-of-interest data from social network for urban land use classification and disaggregation. Computers, Environment and Urban Systems. p. 36 - 46, 2015.

https://doi.org/10.1016/j.compenvurbsys.2014. 12.001.

LONG, Y.; LIU, X. Automated identification and characterization of parcels (AICP) with OpenStreetMap and Points of Interest. Environment and Planning B: Urban Alanytics and Science, v. 43, n. 2, p. 341-360, 2015

https://doi.org/10.1177/0265813515604767.

MALOA, J. M. A urbanização moçambicana contemporânea: sua característica, sua dimensão e seu desafio. Revista Brasileira de Gestão Urbana, v. 11, $2019 . \quad$ https://doi.org/10.1590/21753369.011.e20180101.

MALOA, J. M. e NASCIMENTO JÚNIOR, L. A Dispersão Urbana em Moçambique: Uma Contribuição Ao Estudo Da Produção Do Espaço Urbano Em Maputo. Raega - O Espaço Geográfico em Análise, v. 45, n. 1. p. 91 - 109, 2018.

http://dx.doi.org/10.5380/raega.v45i1.50743.

MELO, V. P. Urbanismo português na cidade de Maputo: passado, presente e futuro. Revista Brasileira de Gestão Urbana, v. 5, n. 1, p. 71 88, 2017. https://doi.org/10.7213/urbe. 7786 .

MILANI, P.; SILVA, E. A. Centralidade Urbana: Um Estudo do Centro Principal de Três Lagoas - MS. Geografia em Atos, v. 1, n. 9, 2009. https://doi.org/10.35416/geoatos.v1i9.26 5.

OPEN STREET MAP. Disponível em: https://www.openstreetmap.org. Acesso em: 08 mai. 2020.

PORTA, S.; CRUCITTI, P.; LATORA, V. The network analysis of urban streets: a primal approach. Environment and Planning B: Planning and Design, v. 33, p. $705-725,2006$. https://doi.org/10.1068/b32045.

SAATY, R. W. The Analytic Hierarchy Process - What Is and How It Is Used. Mat/d Modelling, v. 9, n. 3-5, p. 161-176, 1987. https://doi.org/10.1016/0270-0255(87)90473-8. SANTOS, J. R.; ESPÍNDOLA, E. S.; ESPINOSA, J. M. A. Identificação de Subcentralidade no Espaço Urbano Através de Análise Multicriterial: Estudo de Caso Em Rio Grande/RS. In: Anais do XIX Simpósio Brasileiro de Sensoriamento Remoto, 2019, Santos. Anais eletrônicos... São José dos Campos, INPE, 2019. Disponível em : 
<https://proceedings.science/sbsr-

2019/papers/identificacao-de-

subcentralidades-no-espaco-urbano-atraves-

de-analise-multicriterial--estudo-de-caso-em-

rio-grande-rs>. Acesso em: 03. Outubro. 2020.

SEVTSUK, A.; MEKONNEN, M. Urban network analysis: A new toolbox for ArcGIS. Revista Internacional da Geomática, v. 22, n. $2, \quad$ p. $287 \quad$ - $305, \quad 2012$. http://dx.doi.org/10.3166/rig.22.287-305

SIQUEIRA, L. P. R. Proposta Metodológica Para a Identificação de Subcentros Urbanos: Estudo de Caso na Região Metropolitana de São Paulo. Economia Aplicada, v. 18, n. 1, p. 139-165, 2014. https://doi.org/10.1590/1413-8050/ea476.

SOPHA, B. M.et al. Urban distribution center location: Combination of spatial analysis and multi-objective mixed-integer linear programming. International Journal of Engineering Business Management, v. 8, p. 1 10. 2016. https://doi.org/10.1177/1847979016678371.

TAHERDOOST, H. Decision Making Using the Analytic Hierarchy Process (AHP): A Step by
Step Approach. International Journal of Economics and Management System, v. 2, 2017. https://hal.archives-ouvertes.fr/hal02557320

YU, L.; WU, Y.; WU, G. Rethinking the Identification of Urban Centers from the Perspective of Function Distribution: A Framework Based on Point-of-Interest Data. Sustainability, $\quad$ v. $12, \quad 2020$. https://doi.org/10.3390/su12041543.

ZHONG, C. et al. Revealing Centrality in the Spatial Structure of Cities from Human Activity Patterns. Estudos Urbanos, v. 54, p. $437 \quad$ - $\quad 455, \quad 2015$. http://hdl.handle.net/1721.1/109118.

\section{CONTRIBUIÇÃO DO AUTOR}

Tomé Francisco Chicombo concebeu o estudo, coletou, analisou os dados e redigiu o texto. 